\title{
Notes on Citations and Transliterations
}

The Arabic transliteration in this book follows a modified version of the system advocated by the International Journal of Middle East Studies. Arabic nouns commonly found in the English language are not transliterated; e. g. caliph, harem, Mecca, Medina etc. Transliterated Arabic book titles have the first letter of the first word capitalised only unless this word is kitāb in which case it is the following word with the only capitalised initial letter.

Two elements of Arabic naming conventions have been problematic in connection to the database creation. The first is the 'al-' prefix which - for some names - may or may not appear (the name Zubayr, for instance, can also be al-Zubayr, particularly when it appears in a patriline). The second issue is the orthographic change that effects the Arabic word for 'father' depending on whether it is referring to an individual (where it is the nominative $A b \bar{u}$ ) or appears in a patriline (where it is genitive Abī). This means that 'Alī b. Abì Țālib's father becomes Abū Țālib when we discuss him as an individual. These two elements created significant problems for computer-based searching and ordering so the database dropped the use of the 'al-' prefix in all instances except constructions (e.g. 'Abd al-Malik) and used only the nominative form of 'father'. In this book the grammatically correct version of 'father' has been re-introduced and I have tried to be as consistent as possible with the 'al-"prefix. As for the transliteration of the names I have followed Lévi-Provençal's suggested vowelling in his edition of the Nasab Quraysh.

Numbers from one to ten will be written out; numbers above this will be provided in numerical form. Exceptions to this are numbers as they appear in lists and when used to refer to generations; this is to account for the negative numbers that occasionally appear. Decimals will be given to two places. All dates are Common Era unless otherwise stated though 'CE' will be written after dates in instances where clarity is needed (for instance in a paragraph with a lot of other numbers).

Best efforts have been made to render this work accessible to the non-Arabic reader. To this end, references to translations have been provided where available and plural forms of Arabic words are avoided where practicable. 
